\title{
Cbl participates in shikonin-induced apoptosis by negatively regulating phosphoinositide 3-kinase/protein kinase B signaling
}

\author{
DAN QU ${ }^{1}$, XIAO-MAN XU ${ }^{1}$, MENG ZHANG $^{2}$, TING-SHU JIANG ${ }^{3}$, YI ZHANG $^{2}$ and SHENG-QI LI ${ }^{1}$ \\ Departments of ${ }^{1}$ Respiratory Medicine and ${ }^{2}$ Geriatrics, Shengjing Hospital of China Medical University, \\ Shenyang, Liaoning 110004; ${ }^{3}$ Department of Respiratory Medicine, Yuhuangding Hospital of Qingdao University, \\ Yantai, Shandong 264000, P.R. China
}

Received May 21, 2014; Accepted February 11, 2015

DOI: $10.3892 / \mathrm{mmr} .2015 .3510$

\begin{abstract}
Shikonin, a naturally occurring naphthoquinone, exhibits anti-tumorigenic activity. However, its precise mechanisms of action have remained elusive. In the present study, the involvement in the action of shikonin of the ubiquitin ligases Cbl-b and c-Cbl, which are negative regulators of phosphoinositide 3-kinase (PI3K) activation, was investigated. Shikonin was observed to reduce cell viability and induce apoptosis and $\mathrm{G}_{2} / \mathrm{M}$ phase arrest in lung cancer cells. In addition, shikonin increased the protein levels of B-cell lymphoma 2 (Bcl-2)-associated X and p53 and reduced those of Bcl-2. Additionally, shikonin inhibited PI3k/Akt activity and upregulated $\mathrm{Cbl}$ protein expression. In addition, a specific inhibitor of PI3K, LY294002, was observed to have a synergistic effect on the proliferation inhibition and apoptotic induction of A549 cells with shikonin. In conclusion, the results of the present study suggested that $\mathrm{Cbl}$ proteins promote shikonin-induced apoptosis by negatively regulating PI3K/Akt signaling in lung cancer cells.
\end{abstract}

\section{Introduction}

Lithospermum erythrorhizon, a traditional Chinese herbal medicine, has been used for the treatment of inflammation, tumors and burns for thousands of years (1). Shikonin (SK) is the key active ingredient isolated from the dried roots of Lithospermum erythrorhizon, with a molecular weight of $288 \mathrm{~g} / \mathrm{mol}$ (Fig. 1). As a naphthoquinone pigment, SK exhibits multiple biological activities, including anti-inflammatory, anti-microbial and anti-tumor effects, in addition to antagonism of the human immunodeficiency virus and wound healing-promoting properties $(2,3)$. Previous studies have

Correspondence to: Dr Sheng-Qi Li, Department of Respiratory Medicine, Shengjing Hospital of China Medical University, 36 Sanhao Street, Shenyang, Liaoning 110004, P.R. China

E-mail: lishengqilili@163.com

Key words: shikonin, apoptosis, Cbl, phosphoinositide 3-kinase/Akt, P53 demonstrated that SK induces apoptosis in various types of tumor cell but has no effect on the majority of normal cells $(4,5)$, suggesting that it may provide a novel anti-neoplastic therapeutic treatment strategy.

Various oncogenes and tumor suppressor genes are involved in apoptosis, amongst which the tumor suppressor gene p53 is of particular significance (6). p53 serves an important role in the prevention of tumor occurrence and development via initiating cell cycle arrest and apoptosis in damaged cells, in order to maintain genomic stability (7). The loss of wild-type p53 function may lead to tumor development, and in humans, p53 is known to be mutated or inactivated in at least $50 \%$ of tumors (8-10). Certain studies have demonstrated that SK induces apoptosis in Hela, colorectal carcinoma COLO 205 and malignant melanoma A375-S2 cells, accompanied by upregulated expression levels of p53 protein (11-13). This suggested that SK-mediated apoptosis involves p53 signaling.

However, in order to prolong their survival, tumor cells have developed several mechanisms to inhibit apoptosis. Previous studies have demonstrated that the phosphoinositide 3-kinase (PI3K)/Akt signaling pathway is persistently activated in pre-malignant and malignant human bronchial epithelial cells in addition to non-small cell lung cancer. This is suggested to be due to activating mutations in ras (14-16). In addition, multiple cytotoxic drugs have been reported to induce apoptosis by inhibiting the PI3K/Akt pathway $(17,18)$.

The casitas B-lineage lymphoma (Cbl) family of ubiquitin ligases comprises adaptor proteins and E3 ligases that serve positive and negative roles in several signaling pathways and affect various cellular functions (19). Cbl proteins are known to participate in the regulation of mitogen-activated protein kinases, insulin signaling and PI3K/Akt signaling (19-21). However, it remains elusive whether $\mathrm{Cbl}$ family members are involved in SK-induced apoptosis.

Previous studies have further suggested that reactive oxygen species (ROS) are involved in SK-induced apoptosis in human SK-Hep-1 hepatoma cells and Bcr/Abl-positive chronic myelogenous leukemia cells $(22,23)$. In the human oral squamous cell carcinoma Tca-8113 cell line, induction of apoptosis by SK was demonstrated to be partly mediated via inhibition of the nuclear factor- $\kappa \mathrm{B}$ pathway (24). SK has also been identified to downregulate estrogen receptor- $\alpha$ protein through a proteasome-mediated pathway, and co-treatment 


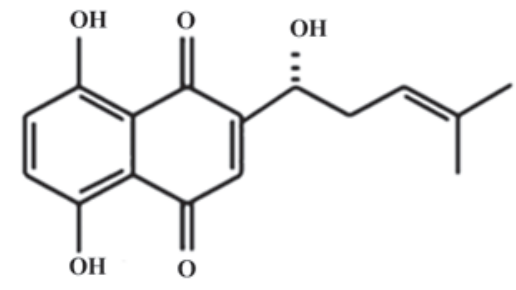

Figure 1. Chemical structure of shikonin.

with SK enhanced sensitivity of breast cancer cells to endocrine therapy (25).

The present study aimed to investigate the mechanisms of SK action in lung cancer A549 cells. The effects of SK on the expression of p53 in A549 cells, in addition to the association between $\mathrm{Cbl}$ and PI3K in SK-induced apoptosis of A549 cells, were examined. Additionally, the involvement of ROS in this process was investigated. It was hypothesized that SK upregulates the expression of $\mathrm{Cbl}$ proteins, which are involved in SK-induced lung cancer cell apoptosis via negative regulation of PI3K/Akt signaling.

\section{Materials and methods}

Reagents and antibodies. Rabbit polyclonal anti-B-cell lymphoma 2 (Bcl-2; cat. no. sc-492), rabbit polyclonal anti-Bcl-2-associated X (Bax, cat.no. sc-493), rabbit polyclonal anti-Cbl-b (cat. no. sc-1704) and rabbit polyclonal anti-p53 (cat. no. sc-6243) antibodies were purchased from Santa Cruz Biotechnology, Inc. (Dallas, TX, USA). Rabbit monoclonal anti-phosphorylated (p)-Akt (Ser-473; cat. no. 3787s), rabbit polyclonal anti-Akt (cat. no. 9272), rabbit monoclonal anti-c-Cbl (cat. no. C49H8) antibodies and the PI3K inhibitor LY294002 were purchased from Cell Signaling Technology, Inc. (Danvers, MA, USA). Rabbit polyclonal anti- $\beta$-actin (cat. no. ab16039) was purchased from Abcam (Cambridge, UK). Goat anti-rabbit horseradish peroxidase-conjugated secondary antibodies (cat. no. A0208) were purchased from Beyotime Institute of Biotechnology (Shanghai, China). SK (>98\% pure) was purchased from the National Institute for the Control of Pharmaceutical and Biological Products (Beijing, China). SK was dissolved in dimethyl sulfoxide (DMSO) at a stock concentration of $100 \mathrm{mM}$, aliquoted and stored at $-20^{\circ} \mathrm{C}$. Fetal bovine serum (FBS) was purchased from Beijing Solarbio Science \& Technology Co., Ltd. (Beijing, China). MTT, DMSO, propidium iodide (PI) and Hoechst 33342 were purchased from Sigma-Aldrich (St. Louis, MO, USA). The annexin V-fluorescein isothiocyanate and propidiumiodide (PI) double staining kit was purchased from Beijing Biosea Biotechnology Co., Ltd. (Beijing, China). Ribonuclease A (RNase A) and ROS assay kit were purchased from Beyotime Institute of Biotechnology.

Cell culture. The human lung adenocarcinoma A549 cells were purchased from the Department of Cell Biology, China Medical University (Shenyang, China). A549 cells were cultured in RPMI 1640 medium (Hyclone, GE Healthcare, Little Chalfont, UK) containing 10\% FBS, $100 \mathrm{U} / \mathrm{ml}$ penicillin and $100 \mu \mathrm{g} / \mathrm{ml}$ streptomycin (Harbin Pharmaceutical Group
Co., Ltd., Harbin, China) at $37^{\circ} \mathrm{C}$ under an atmosphere of $95 \%$ humidity and $5 \% \mathrm{CO}_{2}$. Cells were routinely subcultured every 2-3 days and cell samples used were all in the logarithmic growth phase.

Cell viability assay. Cells were seeded at a density of $1 \times 10^{4}$ cells/well in 96-well plates and were incubated overnight. Subsequently, various concentrations $(0.312-10 \mu \mathrm{M})$ of SK were added and further incubated for 24 and $48 \mathrm{~h}$. Thereafter, $20 \mu 1$ MTT solution $(5 \mathrm{mg} / \mathrm{ml})$ was added to each well and the cells were incubated for an additional $4 \mathrm{~h}$ at $37^{\circ} \mathrm{C}$. Following the removal of culture medium, the cells were lysed in $150 \mu \mathrm{l}$ DMSO and the optical density was measured at $570 \mathrm{~nm}$ using a microplate reader (Model 550; Bio-Rad Laboratories, Inc., Hercules, CA, USA).

Cell cycle analysis. Phase distributions of the cell cycle and hypodiploid DNA were determined by flow cytometry. A549 cells were plated at a density of $1 \times 10^{6}$ cells/well in six-well plates overnight and then treated with 1.5 and $1.8 \mu \mathrm{M} \mathrm{SK}$ for $24 \mathrm{~h}$. Following this, the cells were collected and washed twice with phosphate-buffered saline (PBS; Beyotime Institute of Biotechnology). Subsequent to fixing in ice-cold $70 \%$ ethanol (Shenyang Liaohe Chemical Plant, Shenyang, China) for $12 \mathrm{~h}$, samples were washed twice with PBS and then incubated with RNase A $(20 \mu \mathrm{g} / \mathrm{ml})$ and PI $(10 \mu \mathrm{g} / \mathrm{ml})$ for $30 \mathrm{~min}$ in the dark. Finally, the samples were examined using a FACScan Flow Cytometer and data were analyzed using CellQuest 3.2 software (BD Biosciences, San Jose, CA, USA).

Cell apoptosis analysis. A549 cells were plated at a density of $1 \times 10^{6}$ cells/well in six well plates overnight and were subsequently treated with 1.5 and $1.8 \mu \mathrm{M}$ SK for $24 \mathrm{~h}$. The cells were collected following incubation. At the same time, A549 cells were plated in six well plates $\left(1 \times 10^{6}\right.$ cells/well) overnight. The cells were pretreated with or without $10 \mathrm{nM}$ Ps341 (Active Biochem, Maplewood, NJ, USA), an inhbitor of proteasome and $\mathrm{Cbl}$, for $1 \mathrm{~h}$ and subsequently treated with $1.8 \mu \mathrm{M}$ SK for $24 \mathrm{~h}$, prior to collection. The cells were washed twice with PBS and incubated with $10 \mu \mathrm{l}$ annexin V and $5 \mu \mathrm{l}$ PI for $15 \mathrm{~min}$ in the dark. The samples were evaluated by flow cytometry as described above.

Fluorescence microscopy. A549 cells were treated with 1.5 and $1.8 \mu \mathrm{M}$ SK for $24 \mathrm{~h}$. Subsequently, the cells were collected, washed twice with PBS and fixed in a mixture of cold methanol and acetic acid (3/1, v/v; Shenyang Liaohe Chemical Plant) prior to staining with Hoechst $33342(1 \mathrm{mg} / \mathrm{ml})$ for $30 \mathrm{~min}$ at $37^{\circ} \mathrm{C}$. Stained cells were imaged using a fluorescence microscope (magnification, x400; Eclipse 90i, Nikon Corporation, Tokyo, Japan).

Western blot analysis. The expression of cellular proteins was evaluated by western blotting. Following SK treatment for $4,8,12$ and $24 \mathrm{~h}$, and pretreatment with or without $10 \mathrm{nM}$ Ps341, cells were washed twice with ice-cold PBS and the total proteins were solubilized and extracted with lysis buffer (20 mM HEPES, pH 7.9; 20\% glycerol; $200 \mathrm{mM} \mathrm{KCl}$; $0.5 \mathrm{mM}$ EDTA; $0.5 \%$ NP40; $0.5 \mathrm{mM}$ DTT and $1 \%$ protease inhibitor cocktail; Shanghai Jining Industrial Co., Ltd.). The 
Table I. Cell cycle distribution of A549 cells incubated with SK for $24 \mathrm{~h}$.

\begin{tabular}{lcrr}
\hline $\mathrm{SK}(\mu \mathrm{M})$ & $\mathrm{G}_{1}(\%)$ & $\mathrm{S}(\%)$ & $\mathrm{G}_{2} / \mathrm{M}(\%)$ \\
\hline 0 & $77.84 \pm 6.28$ & $16.74 \pm 2.34$ & $5.42 \pm 1.06$ \\
1.5 & $53.84 \pm 4.86$ & $33.51 \pm 4.87$ & $12.65 \pm 2.24$ \\
1.8 & $55.99 \pm 4.03$ & $26.74 \pm 2.78$ & $17.27 \pm 3.27$ \\
\hline
\end{tabular}

Values are presented as the mean \pm standard deviation. SK, shikonin.

protein concentration was determined by the bicinchoninic acid protein assay (Beyotime Institute of Biotechnology). Equal amounts of protein $(50 \mu \mathrm{g})$ from each sample were separated using 12\% SDS-PAGE (Beyotime Institute of Biotechnology, Shanghai, China). Following electrophoresis, the proteins were electroblotted to polyvinylidene difluoride membranes (Beyotime Institute of Biotechnology). The membranes were blocked with 5\% nonfat dry milk dissolved in TBST (20 mM Tris-buffered saline, pH 7.5 containing $1 \mathrm{~g} / 1$ Tween 20; Beyotime Institute of Biotechnology) at room temperature and then independently incubated at $4^{\circ} \mathrm{C}$ overnight with primary antibodies against Bcl-2 (1:300), Bax (1:300), p53 (1:1,000), Akt $(1: 1,000)$, p-Akt $(1: 1,000)$, c-Cbl $(1: 1,000)$ or Cbl-b $(1: 250)$, and $\beta$-actin $(1: 1,000)$ was used as a control. Subsequent to washing three times with TBST, the membranes were incubated with goat anti-rabbit horseradish peroxidase-conjugated secondary antibodies (1:800) at $37^{\circ} \mathrm{C}$ for $30 \mathrm{~min}$, followed by a further three washes with TBST. Protein bands were visualized using an enhanced chemiluminescence reagent (Thermo Fisher Scientific, Waltham, MA, USA).

Intracellular ROS measurement. A549 cells were treated with 1.5 and $1.8 \mu \mathrm{M}$ SK for $24 \mathrm{~h}$ and were then collected. Dichloro-dihydro-fluorescein diacetate (DCFH-DA; $10 \mu \mathrm{M}$ ) was diluted at 1:1,000 with serum-free RPMI-1640 medium (Gibco Life Technologies, Grand Island, NY, USA). The cells were suspended in $1 \mathrm{ml}$ diluted DCFH-DA, then incubated in a $37^{\circ} \mathrm{C}$ cell incubator for $20 \mathrm{~min}$ with inversion every 3-5 min to maximize contact between the probe and the cells. Following this, the cells were washed with serum-free cell culture medium three times and the intracellular $\mathrm{H}_{2} \mathrm{O}_{2}$ concentration was determined using a FACScan flow cytometer (BD Biosciences).

Statistical analysis. Values are expressed as the mean \pm standard deviation. Statistical correlation was evaluated by an analysis of variance and Student's t-test, where $\mathrm{P}<0.05$ was considered to indicate a statistically significant difference. These analyses were performed using SPSS software, version 17.0 (SPSS, Inc., Chicago, IL, USA).

\section{Results}

SK induces growth inhibition of A549 cells. To determine whether SK inhibits proliferation of lung cancer cells, A549 cells were treated with different concentrations of SK (0.312-10 $\mu \mathrm{M})$ for 24 and $48 \mathrm{~h}$. A significant dose-dependent and time-dependent reduction of viability was observed

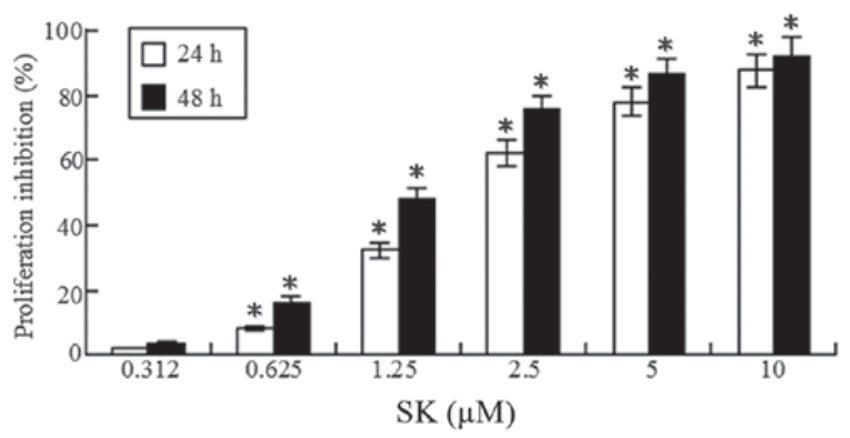

Figure 2. The inhibitory effects of SK on human lung cancer A549 cell proliferation. Logarithmically growing A549 cells were treated with the indicated concentrations of SK for either 24 or $48 \mathrm{~h}$. Cell viability was then assessed by MTT assay. ${ }^{*} \mathrm{P}<0.01$ vs. control group. SK, shikonin.

(Fig. 2). The $50 \%$ inhibitory concentration of cells $\left(\mathrm{IC}_{50}\right)$ at 24 and $48 \mathrm{~h}$ was $1.75 \pm 0.26$ and $1.25 \pm 0.17 \mu \mathrm{M}$, respectively.

SK induces $G_{2} / M$ cell cycle arrest in A549 cells. To determine whether SK inhibits cell cycle progression in A549 cells, the cells were treated with different concentrations of SK for $24 \mathrm{~h}$. Flow cytometric analysis demonstrated that treatment with SK induced significant $\mathrm{G}_{2} / \mathrm{M}$ cell cycle arrest (Fig. 3). The percentages of cells in $\mathrm{G}_{2} / \mathrm{M}$ phase were $5.42 \pm 1.06 \%, 12.65 \pm 2.24 \%$ and $17.27 \pm 3.27 \%$ following treatment with $0,1.5$ and $1.8 \mu \mathrm{M}$ SK, respectively (Table I). Differences between treated and untreated cells were statistically significant $(\mathrm{P}<0.01)$.

SK induces A549 cell apoptosis. To determine whether SK induces apoptosis in A549 cells, SK-induced cytotoxicity was investigated. Flow cytometric analysis of annexin-V and PI demonstrated that SK induced significant apoptosis in A549 cells. The percentages of double-stained cells, indicative of apoptosis, were $17.20 \pm 2.26 \%(\mathrm{P}<0.01)$ and $21.98 \pm 2.26 \%$ $(\mathrm{P}<0.01)$ at 1.5 and $1.8 \mu \mathrm{M} \mathrm{SK}$, respectively, compared with $2.91 \pm 0.21 \%$ in the non-treated control (Fig. 4). Consistent with these results, confocal fluorescence microscopy also identified clear morphological alterations typical of apoptosis, including condensation of chromatin and nuclear fragmentations following treatment of cells with SK (Fig. 5).

SK upregulates $p 53$ and alters the Bax/Bcl-2 ratio in favor of apoptosis. To determine the mechanism of SK-induced A549 cell apoptosis, the expression levels of apoptosis-associated proteins were investigated. Following incubation with either 1.5 or $1.8 \mu \mathrm{M} \mathrm{SK}$ for $24 \mathrm{~h}$, the expression of the anti-apoptotic $\mathrm{Bcl}-2$ protein was significantly 

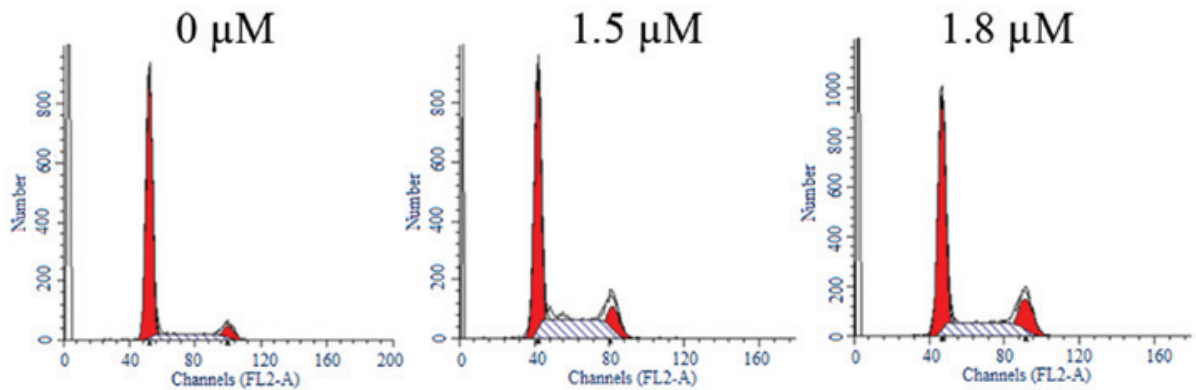

Figure 3. Induction of $\mathrm{G}_{2} / \mathrm{M}$ phase arrest in A549 cells by SK. A549 cells were treated with the indicated concentrations of SK for $24 \mathrm{~h}$. Alterations in cell cycle phase distribution were then assessed by propidium iodide staining and flow cytometric analysis. SK, shikonin.
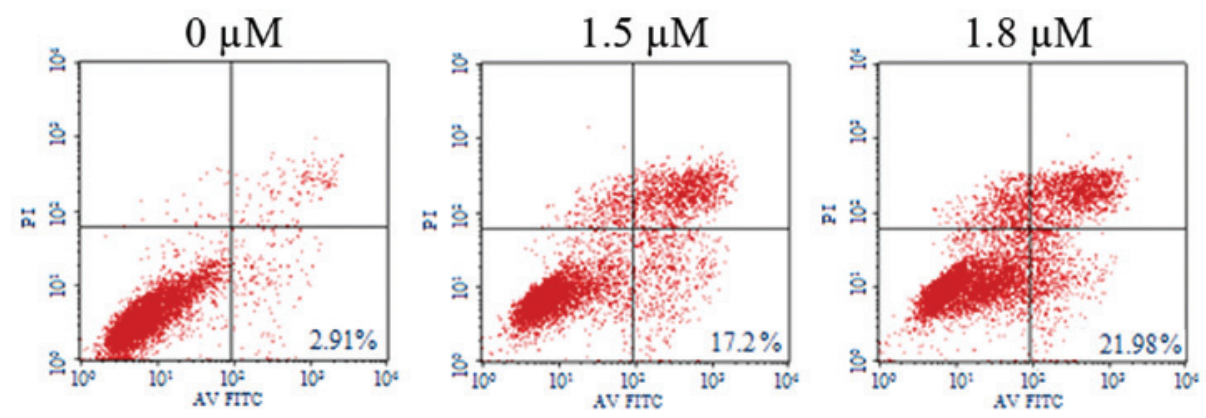

Figure 4. Analysis of apoptotic cells by flow cytometry. A549 cells were treated with the indicated concentrations of SK for $24 \mathrm{~h}$. Alterations in cell apoptosis distribution were assessed by AV-FITC/PI staining followed by flow cytometric analysis. The percentages of apoptotic (double stained) cells are indicated. SK, shikonin; AV, annexin V; FITC, fluorescein isothiocyanate; PI, propidium iodide.
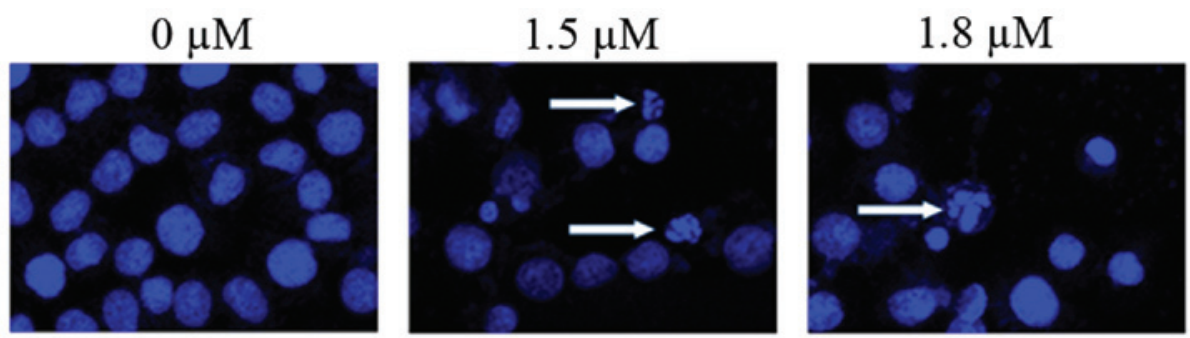

Figure 5. Analysis of apoptotic cells by fluorescence microscopy. A549 cells were treated with the indicated concentrations of shikonin for $24 \mathrm{~h}$, then apoptosis was observed by Hoechst 33342 staining and analysis by confocal microscopy. Chromatin condensation and nuclear fragmentation are indicated by the white arrowheads. Magnification, x400.

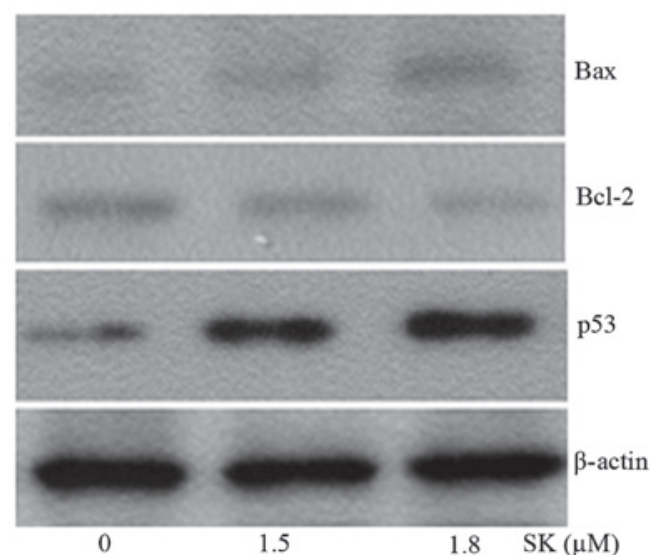

Figure 6. Effects of SK on the expression levels of apoptosis-associated proteins in A549 cells. A549 cells were treated with the indicated concentrations of SK for $24 \mathrm{~h}$. Bax, Bcl-2 and p53 protein expression levels were then analyzed by western blotting. Expression of $\beta$-actin served as the control. SK, shikonin; Bcl-2, B-cell lymphoma 2; Bax, Bcl-2-associated X protein.

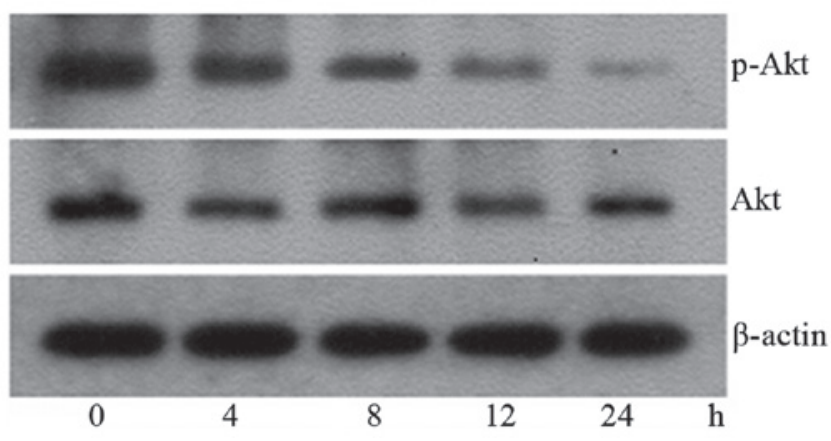

Figure 7. Effects of SK on phosphoinositide 3-kinase/Akt signaling pathways in A549 cells. A549 cells were treated with $1.8 \mu \mathrm{M}$ SK for the indicated time-points, and p-Akt and Akt protein expression levels were analyzed by western blotting. $\beta$-actin protein expression levels served as the control. SK, shikonin; Akt, protein kinase B; p-Akt, phosphorylated Akt. 


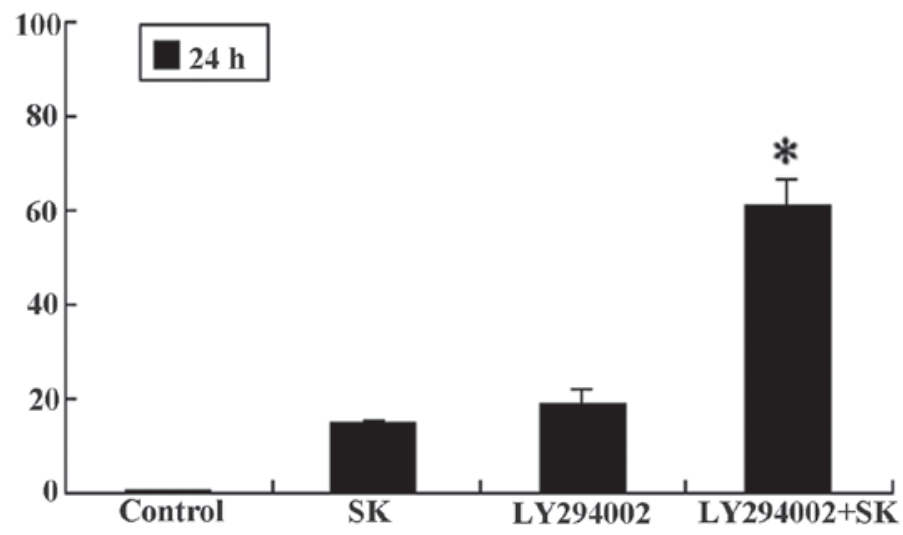

Figure 8. Effects of co-treatment with LY294002 and SK on inhibition of A549 cell proliferation. A549 cells were pretreated with the phosphoinositide 3-kinase/protein kinase B inhibitor LY294002 for $1 \mathrm{~h}$, then $1.0 \mu \mathrm{M} \mathrm{SK}$ was added for $24 \mathrm{~h}$. The inhibition of proliferation was measured by an MTT assay, ${ }^{*} \mathrm{P}<0.01$ vs. cells treated with either LY294002 or SK alone. SK, shikonin.
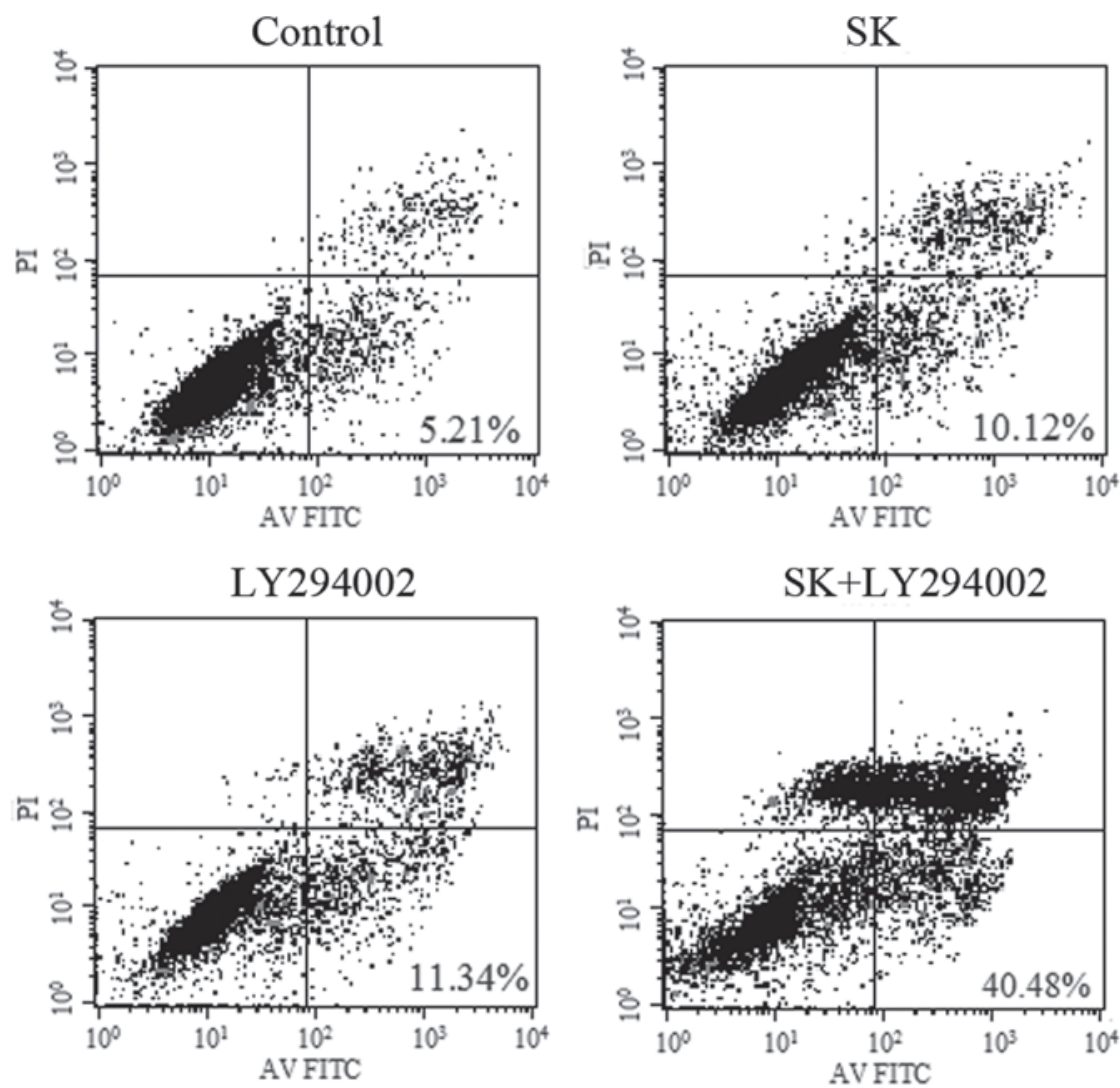

Figure 9. Effects of co-treatment with LY294002 and SK on apoptotic induction in A549 cells. A549 cells were pre-treated with phosphoinositide 3-kinase/protein kinase B inhibitor LY294002 for $1 \mathrm{~h}$, then $1.0 \mu \mathrm{M}$ SK was added for $24 \mathrm{~h}$. Cell apoptosis was assessed by AV-FITC/PI staining and flow cytometry. The percentages of apoptotic cells are indicated. SK, shikonin; AV, annexin V; FITC, fluorescein isothiocyanate; PI, propidium iodide.

reduced, whereas the expression of pro-apoptotic Bax protein was significantly increased (Fig. 6). SK treatment significantly increased the $\mathrm{Bax} / \mathrm{Bcl}-2$ ratio. It was hypothesized that $\mathrm{p} 53$ also served an important role in SK-induced apoptosis. To investigate this, the protein levels of p53 were examined in cells treated with SK. SK was observed to increase the intracellular levels of p53 in a dose-dependent manner (Fig. 6).

SK induces A549 cell apoptosis by inhibiting PI3K/Akt signaling and potentiates LY294002-mediated inhibition of proliferation and apoptosis. To further determine the mechanism of SK-induced apoptosis in A549 cells, the levels of p-Akt and total Akt protein following treatment with $1.8 \mu \mathrm{M}$ SK for 4-24 h were measured. It was observed that the expression levels of p-Akt protein started to reduce at $4 \mathrm{~h}$ and reached a minimum at $24 \mathrm{~h}$ (Fig. 7). This suggested that SK induces A549 cell apoptosis by inhibiting the PI3K/Akt signaling pathway. Additionally, 1-h pre-treatment of A549 cells with LY294002, a specific inhibitor of PI3K, followed by the addition of $1 \mu \mathrm{M}$ SK (a sub-toxic dose), resulted in an increase 


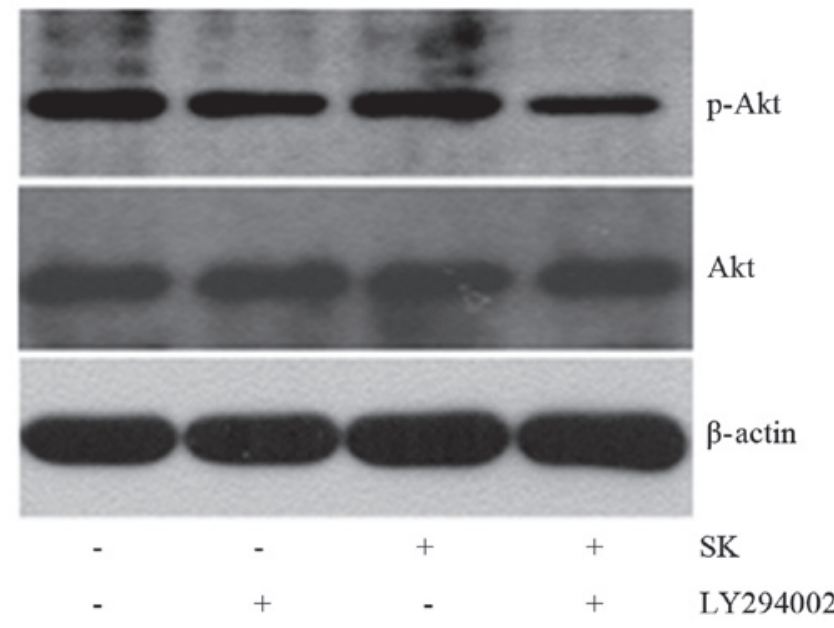

Figure 10. Effects of co-treatment with LY294002 and SK on Akt activation in A549 cells. A549 cells were pretreated with the phosphoinositide 3-kinase/Akt inhibitor LY294002 for $1 \mathrm{~h}$, then $1.0 \mu \mathrm{M}$ SK was added for $24 \mathrm{~h}$. p-Akt and Akt protein expression levels were analyzed by western blotting, where $\beta$-actin served as a control. SK, shikonin; Akt, protein kinase B; p-Akt, phosphorylated-Akt.
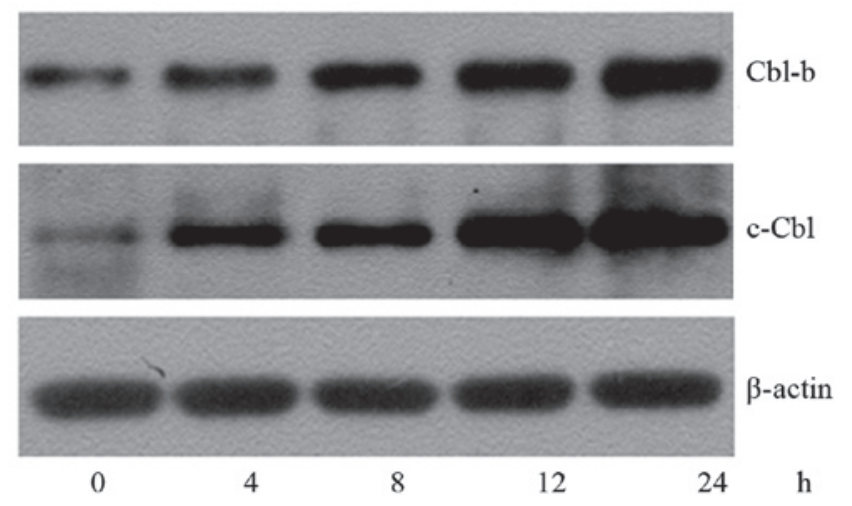

Figure 11. Effect of SK on the expression of Cbl-b and c-Cbl proteins in A549 cells. A549 cells were treated with $1.8 \mu \mathrm{M}$ shikonin for $4-24 \mathrm{~h}$, as indicated. The alterations in the protein expression levels of Cbl-b and c-Cbl were assessed by western blotting. $\beta$-actin served as a control for input and equal loading. SK, shikonin.

in proliferation inhibition. The proliferation inhibition of cells significantly increased from $17.06 \pm 1.46$ and $19.47 \pm 3.32 \%$ in cells treated with SK alone and LY294002 alone, respectively, to $62.46 \pm 5.12 \%$ in cells treated with both SK and LY294002 $(\mathrm{P}<0.01)$ (Fig. 8). In line with these observations, in identically treated cells, apoptosis was identified to increase from $10.12 \pm 2.48$ and $11.34 \pm 3.38 \%$ to $40.68 \pm 6.46 \%$ ( $P<0.01$ ) (Fig. 9), while the expression levels of $\mathrm{p}$-Akt protein were significantly reduced (Fig. 10). These data suggested that LY294002 and SK have a synergistic effect, leading to enhanced inhibition of proliferation and induction of apoptosis in A549 cells.

Cbl-b and $c$-Cbl are involved in SK-induced A549 cell apoptosis by negatively regulating PI3K/Akt signaling. To investigate whether the inactivation of Akt was associated with $\mathrm{Cbl-b}$ and c-Cbl, their protein expression levels were assessed using western blotting (Fig. 11). In A549 cells treated with $1.8 \mu \mathrm{M}$ SK for 4-24 h, the expression levels of the Cbl-b and
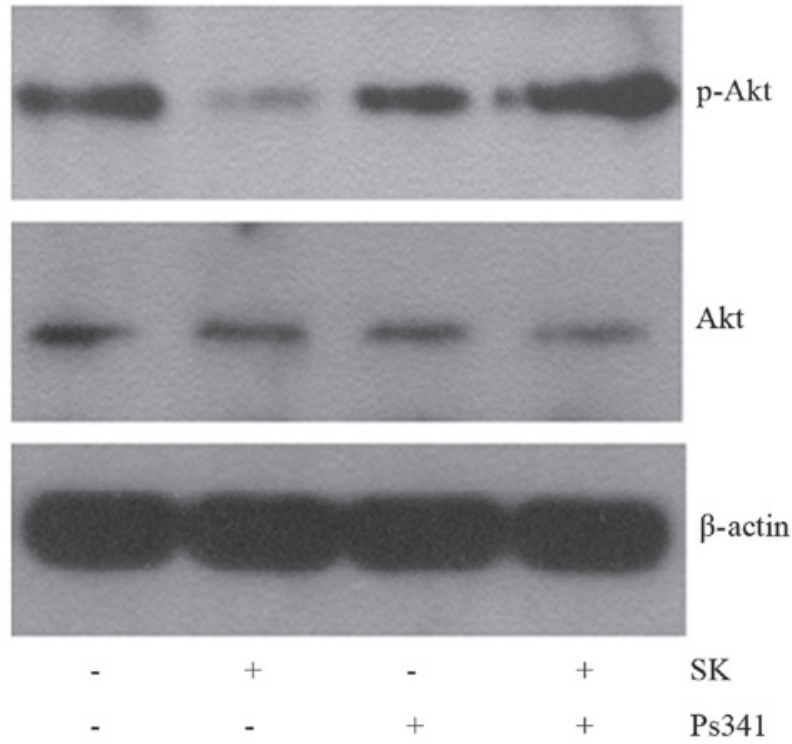

Figure 12. Effects of the combined application of Ps341 and SK on the expression of p-Akt and Akt proteins. A549 cells were pretreated with the proteasome inhibitor Ps341 for $1 \mathrm{~h}$, then $1.8 \mu \mathrm{M}$ SK was added for a further $24 \mathrm{~h}$. The protein expression levels of p-Akt, Akt and $\beta$-actin were analyzed by western blotting. SK, shikonin; Akt, protein kinase B; p-Akt, phosphorylated-Akt.

c-Cbl proteins were demonstrated to begin to increase at $4 \mathrm{~h}$, reaching a maximum at $24 \mathrm{~h}$. The time taken for the upregulation of Cbl-b and c-Cbl proteins was in accordance with that required for the downregulation of the p-Akt protein. This indicated that the inactivation of Akt was likely to be associated with the upregulation of Cbl-b and c-Cbl. To confirm this hypothesis, A549 cells were pre-treated with the proteasome inhibitor Ps341 and Cbl for $1 \mathrm{~h}$, then $1.8 \mu \mathrm{M} \mathrm{SK}$ was added for a further $24 \mathrm{~h}$. Ps341 was observed to reverse SK-induced downregulation of p-Akt (Fig. 12) and apoptosis of A549 cells (Fig. 13). These data suggested that Cbl family members may be involved in SK-induced A549 cell apoptosis via negatively regulating PI3K/Akt signaling.

ROS is not involved in SK-induced apoptosis. To address whether SK enhances ROS generation in A549 cells, the intracellular $\mathrm{H}_{2} \mathrm{O}_{2}$ concentration was detected by DCFH-DA treatment and flow cytometric analysis. As presented in Fig. 14, significant alterations in the ROS concentration were not observed in cells treated with either 1.5 or $1.8 \mu \mathrm{M}$ SK for $24 \mathrm{~h}$. This result indicated that ROS does not participate in SK-induced apoptosis in A549 cells.

\section{Discussion}

SK, one of the major naphthoquinone pigments isolated from the traditional Chinese herb Lithospermum erythrorhizon, has various biological functions. It is associated with anti-microbial, anti-inflammatory and anti-tumor activities, in addition to the promotion of wound healing. Previous studies have demonstrated that SK is able to induce apoptosis in liver cancer, osteosarcoma and prostate cancer cells while its effect on normal cells is minimal. Thus use of SK may provide a novel approach to the treatment of tumors (26-28). The results 

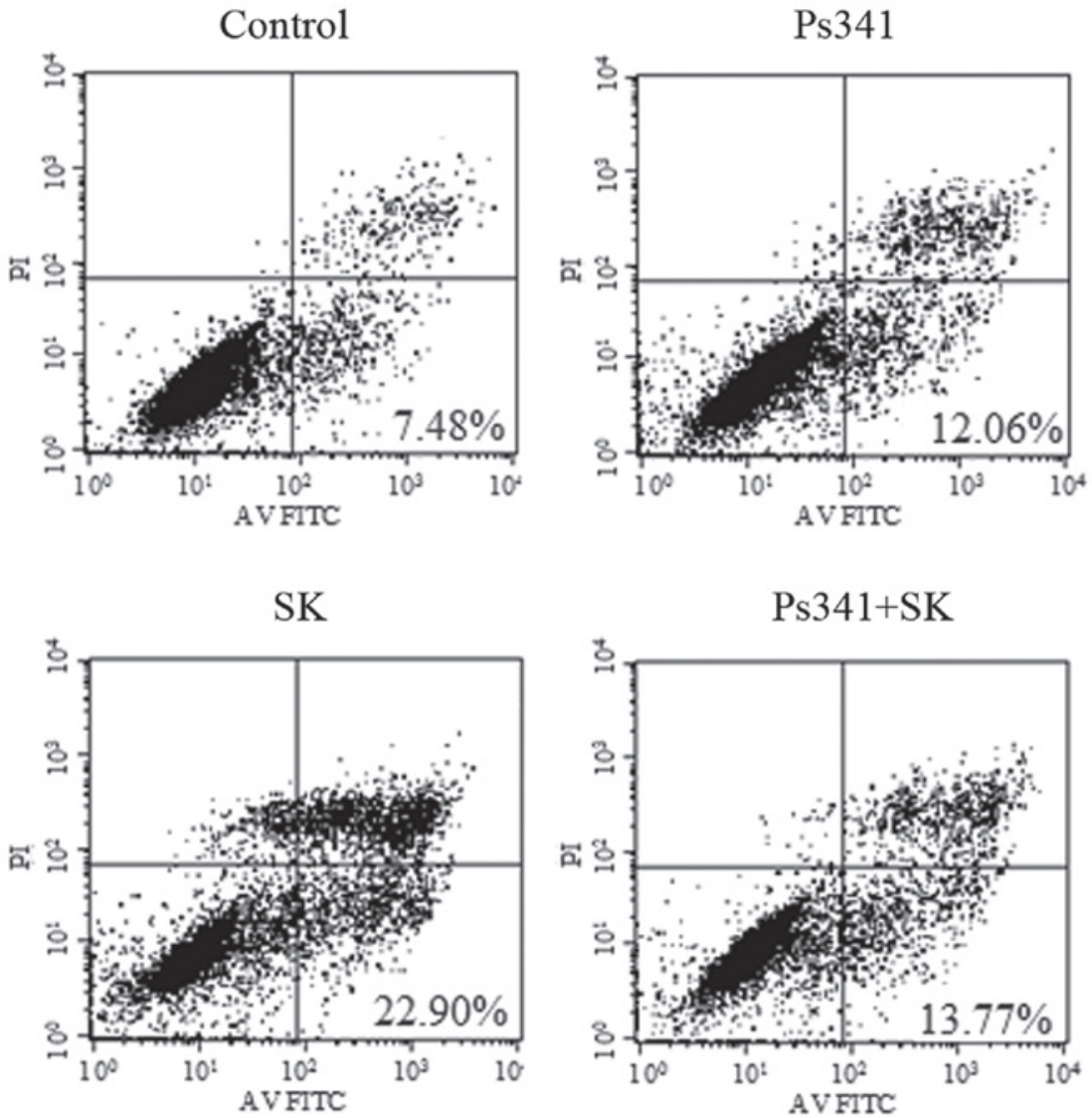

Figure 13. Effects of the combined application of Ps341 and SK on apoptotic induction in A549 cells. A549 cells were pre-treated with the proteasome inhibitor Ps341 for $1 \mathrm{~h}$, then $1.8 \mu \mathrm{M}$ SK was added for a further $24 \mathrm{~h}$. The alterations in the cell apoptosis distribution were assessed by AV-FITC/PI staining followed by flow cytometric analysis. The percentages of apoptotic cells are indicated. SK, shikonin; AV, annexin V; FITC, fluorescein isothiocyanate; PI, propidium iodide.
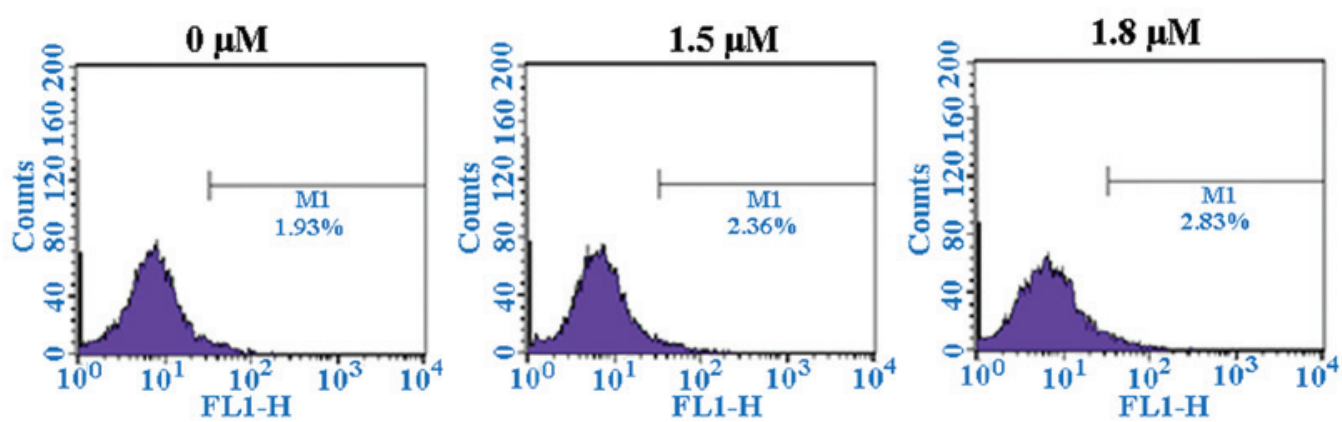

Figure 14. Effect of SK on reactive oxygen species production. A549 cells were treated with either 1.5 or $1.8 \mu \mathrm{M} \mathrm{SK}$ for $24 \mathrm{~h}$, and the intracellular $\mathrm{H}_{2} \mathrm{O}_{2}$ concentration was then detected by flow cytometry. SK, shikonin; MI, intracellular $\mathrm{H}_{2} \mathrm{O}_{2}$ concentration.

of the present study indicated that SK inhibits A549 cell proliferation in a time- and dose-dependent manner. SK was also observed to induce cell apoptosis and $\mathrm{G}_{2} / \mathrm{M}$ phase cell cycle arrest. Several previous studies have investigated SK-induced cell cycle arrest. SK has been demonstrated to induce cell cycle arrest in the $S$ phase of $\mathrm{HepG}_{2}$ cells (26) and in the $\mathrm{G}_{0} / \mathrm{G}_{1}$ phase of human bladder cancer cells (4). Additionally, SK has been identified to inhibit the cell cycle transition from $\mathrm{G}_{1}$ to $S$ phase in Hela cells (29). These results indicate that there is cell specificity in the effect of SK on cell cycle arrest.

Apoptosis is the programmed cell death, which is regulated by certain genes (30). Apoptotic cells have unique morphology, characterized by cell atrophy, loss of connection between cells and chromatin condensation (31). Integration of the apoptotic signal is predominantly mediated by $\mathrm{Bcl}-2$ family proteins and occurs at the mitochondrial level (32). The abnormal expression of Bcl-2 family members, including the pro-apoptotic proteins Bax, $\mathrm{Bcl}-2$ homologous antagonist killer (Bak), Bcl-2-associated death promoter (Bad), BH3 interacting-domain death agonist, Bcl-2-interacting killer, Bcl-2-like protein 11, Harakiri and the anti-apoptotic proteins Bcl-2, Bcl-2 extra large protein (Bcl-xL), Bcl-2-related protein $\mathrm{A} 1$ and myeloid cell leukemia 1, which are represented by Bax and Bcl-2, respectively, can aid tumor cells in evading apoptosis and continuing to proliferate (33). The ratio of $\mathrm{Bcl}-2 / \mathrm{Bax}$ is suggested to be a critical factor which 
determines the apoptosis threshold (34). It has been reported that in SK-induced apoptosis of Tca-8113 and HepG2 cells, the expression of Bcl-2 protein is reduced $(24,26)$, while that of Bax is increased. Similarly, it has been demonstrated that SK-induced COLO 205 cell apoptosis is accompanied by the upregulation of Bad and downregulation of Bcl-2 and Bcl-xL, while having no effect on Bax protein expression levels (29). The present study observed that SK treatment resulted in a significant reduction in Bcl-2 protein expression and a significant increase in Bax protein production in A549 cells. It was therefore hypothesized that SK-mediated inhibition of tumor cell growth is achieved by its ability to modulate the ratio of Bcl-2/Bax.

The p53 gene is vital in preventing damaged or otherwise abnormal cells from becoming malignant (12). Mutation factor induced-DNA damage is able to promote rapid p53 gene product accumulation and the subsequent induction of $\mathrm{G}_{1}$ phase cell cycle arrest (35). p53 can also sequester proliferating cell nuclear antigen, which inhibits the replication of DNA and thereby allows time for DNA to be repaired. If the damage cannot be repaired, p53 is able to induce apoptosis and remove the mutant cells (36). Additionally, p53 is involved in the mechanisms of apoptosis of tumor cells induced by various drugs, including that mediated by wogonin and arsenic trioxide (37,38). The results of the present study demonstrated that the protein expression levels of p53 were increased in SK-treated A549 cells, and that the time required for p53 to increase coincided with that for the increased ratio of $\mathrm{Bax} / \mathrm{Bcl}-2$. It has also been reported that p53 can interact physically with Bcl-2 and Bcl-xL via its DNA-binding domain, which leads to the isolation of these proteins from their pro-apoptotic partners Bax/Bak. These proteins subsequently form oligomers and increase the permeability of the mitochondrial membrane, which leads to cytochrome $\mathrm{C}$ release into the cytoplasm and cell apoptosis (39). Thus, it is suggested that SK first upregulates the expression of the p53 protein, then subsequently increases the ratio of $\mathrm{Bax} / \mathrm{Bcl}-2$ in order to induce $\mathrm{A} 549$ cell apoptosis.

The PI3K/Akt signal transduction pathway is an important intracellular cascade which promotes proliferation and inhibits apoptosis by affecting the activity of downstream effector molecules, including cell cycle regulatory proteins and apoptosis-associated proteins (40). This pathway additionally serves important roles in tumor cell proliferation, angiogenesis and metastasis $(41,42)$. The PI3K/Akt pathway is overactive in certain types of cancer cell, while its inhibition may increase the sensitivity of tumor cells to cytotoxic drugs and induce apoptosis (43). In the present study, treatment of A549 cells with $1.8 \mu \mathrm{M}$ SK for 4-24 $\mathrm{h}$ gradually reduced the protein expression of $\mathrm{p}$-Akt, whereby expression reached a minimum at $24 \mathrm{~h}$. Typical apoptosis was observed at $24 \mathrm{~h}$, suggesting that SK first inhibited the PI3K/Akt pathway, which in turn blocked its regulation of downstream factors, resulting in the loss of PI3K/Akt pathway-mediated anti-apoptotic function, and thus A549 cell apoptosis. This indicates that inhibition of the PI3K/Akt pathway is likely to be one of the mechanisms by which SK induces A549 cell apoptosis. The association between SK and PI3K signaling in apoptotic induction of A549 cells was further investigated using a specific inhibitor of PI3K, LY294002, which inhibits the catalytic activity of the P110s subunit. The results demonstrated that while $1 \mu \mathrm{M}$ SK resulted in a non-significant reduction in cell viability and no greater than $11 \%$ cell apoptosis, treatment with SK plus LY294002 for $24 \mathrm{~h}$ resulted in a significant reduction in cell viability and increased cell apoptosis to $40 \%$ compared with treatment with SK or LY294002 alone. These results indicated that LY294002 and SK have a synergistic effect on the proliferation inhibition and apoptotic induction of A549 cells.

The Cbl family members c-Cbl and Cbl-b, function as E3 ubiquitin ligases that are able to interact with PI3K and modulate its activity in various cell lines (16). By contrast, inhibition of Cbl-PI3K interaction alters bone homeostasis, affecting osteoclast function and osteoblast proliferation (37). Cbl is additionally involved in arsenic trioxide-induced NB4 cell apoptosis and $\mathrm{G}_{2} / \mathrm{M}$ arrest in gastric cancer cells via the inhibition of the PI3K/Akt signaling pathway (15). The results of the present study demonstrated that the protein expression levels of $\mathrm{c}-\mathrm{Cbl}$ and Cbl-b began to increase following exposure of A549 cells to $1.8 \mu \mathrm{M}$ SK for $4 \mathrm{~h}$, and reached maximal expression at $24 \mathrm{~h}$. The kinetics associated with the upregulation of $\mathrm{c}-\mathrm{Cbl}$ and $\mathrm{Cbl}-\mathrm{b}$ corresponded to Akt inhibition, suggesting that SK is likely to promote PI3K ubiquitination via the upregulation of $\mathrm{c}-\mathrm{Cbl}$ and Cbl-b expression. This in turn inhibited Akt activity and finally induced A549 cell apoptosis. Ps341, a Cbl antagonist, was used to pre-treat A549 cells prior to the addition of SK, and this was identified to reverse SK-induced cell apoptosis in addition to the inhibition of p-Akt activity. These observations suggested that c-Cbl and Cbl-b are involved in SK-induced A549 cell apoptosis via the negative regulation of PI3K/Akt activity.

It has previously been demonstrated that treatment with SK induces ROS generation, increases extracellular signal-regulated kinase phosphorylation and reduces Bcl-2 expression. Additionally, pre-treatment with the antioxidant agent $N$-acetyl cysteine has been observed to reverse SK-induced ROS generation and significantly attenuate the cytotoxic effects of SK on 143B osteosarcoma cells (27). SK has also been demonstrated to induce human hepatocellular carcinoma Huh7 and BEL7402 cell apoptosis through the ROS/Akt pathways (44). However, in the present study, ROS was not identified to be involved in SK-induced A549 cell apoptosis, suggesting that the involvement of ROS in SK-induced apoptosis may be cell type-specific.

In conclusion, the present study demonstrated that SK, a naturally occurring naphthoquinone, inhibits proliferation, induces $\mathrm{G}_{2} / \mathrm{M}$-phase arrest and induces apoptosis in A549 cells. SK induced A549 cell apoptosis by promoting the p53-mediated increase of the Bax/ Bcl-2 ratio in favor of apoptosis. The ligases c-Cbl and Cbl-b additionally participated in SK-induced apoptosis in A549 cells by negatively regulating the PI3K/Akt signaling pathway.

\section{References}

1. Han W, Li L, Qiu S, Lu Q, Pan Q, Gu Y, Luo J and Hu X: Shikonin circumvents cancer drug resistance by induction of a necroptotic death. Mol Cancer Ther 6: 1641-1649, 2007.

2. Chen HM, Wang PH, Chen SS, Wen CC, Chen YH, Yang WC and Yang NS: Shikonin induces immunogenic cell death in tumor cells and enhances dendritic cell-based cancer vaccine. Cancer Immunol Immunother 61: 1989-2002, 2012.

3. Chen X, Yang L, Zhang N, Turpin JA, Buckheit RW, Osterling C, Oppenheim JJ and Howard OM: Shikonin, a component of chinese herbal medicine, inhibits chemokine receptor function and suppresses human immunodeficiency virus type 1 . Antimicrob Agents Chemother 47: 2810-2816, 2003. 
4. Yeh CC, Kuo HM, Li TM, Lin JP, Yu FS, Lu HF, Chung JG and Yang JS: Shikonin-induced apoptosis involves caspase-3 activity in a human bladder cancer cell line (T24). In vivo 21: 1011-1019, 2007.

5. Wiench B, Eichhorn T, Paulsen M and Efferth T: Shikonin directly targets mitochondria and causes mitochondrial dysfunction in cancer cells. Evid Based Complement Alternat Med 2012: 726025, 2012.

6. Lago CU, Sung HJ, Ma W, Wang PY and Hwang PM: p53, aerobic metabolism, and cancer. Antioxid Redox Signal 15: 1739-1748, 2011.

7. Vogelstein B, Lane D and Levine AJ: SUrfing the p53 network. Nature 408: 307-310, 2000

8. Levine AJ: p53, the cellular gatekeeper for growth and division. Cell 88: 323-331, 1997.

9. Nigro JM, Baker SJ, Preisinger A, et al: Mutations in the p53 gene occur in diverse human tumor types. Nature 342: 705-708, 1989.

10. Ryan KM, Phillips AC and Vousden KH: Regulation and function of the p53 tumor suppressor protein. Curr Opin Cell Biol 13: 332-337, 2001.

11. Wu Z, Wu LJ, Tashiro S, Onodera S and Ikejima T: Phosphorylated extracellular signal-regulated kinase up-regulated p53 expression in shikonin-induced HeLa cell apoptosis. Chin Med J 118: 671-677, 2005

12. Hsu PC, Huang YT, Tsai ML, Wang YJ, Lin JK and Pan MH: Induction of apoptosis by shikonin through coordinative modulation of the Bcl-2 family, p27 and p53, release of cytochrome $\mathrm{c}$ and sequential activation of caspases in human colorectal carcinoma cells. J Agric Food Chem 52: 6330-6337, 2004.

13. Wu Z, Wu L, Li L, Tashiro S, Onodera S and Ikejima T: p53-mediated cell cycle arrest and apoptosis induced by shikonin via a caspase-9-dependent mechanism in human malignant melanoma A375-S2 cells. J Pharmacol Sci 94: 166-176, 2004.

14. Tsao AS, McDonnell T, Lam S, Putnam JB, Bekele N, Hong WK and Kurie JM: Increased phospho-AKT (Ser (473)) expression in bronchial dysplasia: implications for lung cancer prevention studies. Cancer Epidemiol Biomarkers Prev 12: 660-664, 2003.

15. Brognard J, Clark AS, Ni Y and Dennis PA: Akt/protein kinase $B$ is constitutively active in non-small cell lung cancer cells and promotes cellular survival and resistance to chemotherapy and radiation. Cancer Res 61: 3986-3997, 2001.

16. Massion PP, Taflan PM, Shyr Y, et al: Early involvement of the phosphatidylinositol 3-kinase/Akt pathway in lung cancer progression. Am J Respir Crit Care Med 170: 1088-1094, 2004.

17. Rasul A, Yu B, Khan M, Zhang K, Iqbal F, Ma T and Yang H: Magnolol, a natural compound, induces apoptosis of SGC-7901 human gastric adenocarcinoma cells via the mitochondrial and PI3K/Akt signaling pathways. Int J Oncol 40: 1153-1161, 2012.

18. Jung KH, Choi MJ, Hong S, Lee H, Hong SW, Zheng HM, Lee HS, Hong S and Hong SS: HS-116, a novel phosphatidylinositol 3-kinase inhibitor induces apoptosis and suppresses angiogenesis of hepatocellular carcinoma through inhibition of the PI3K/AKT/mTOR pathway. Cancer Lett 316: 187-195, 2012.

19. Swaminathan $\mathrm{G}$ and Tsygankov AY: The Cbl family proteins: ringleaders in regulation of cell signaling. J Cell Physiol 209: 21-43, 2006

20. Naramura M, Band V and Band $\mathrm{H}$ : Indispensable roles of mammalian Cbl family proteins as negative regulators of protein tyrosine kinase signaling: Insights from in vivo models. Commun Integr Biol 4: 159-162, 2011.

21. Thien CB, Dagger SA and Steer JH: c-Cbl promotes T cell receptor-induced thymocyte apoptosis by activating the phosphatidylinositol 3-kinase/Akt Pathway. J Biol Chem 285: 10969-10981, 2010

22. Mao X, Yu CR, Li WH and Li WX: Induction of apoptosis by shikonin through a ROS/JNK-mediated process in Bcr/Abl-positive chronic myelogenous leukemia (CMl) cells. Cell Res 18: 879-888, 2008.

23. Chen CH, Chern CL, Lin CC, Lu FJ, Shih MK, Hsieh PY and Liu TZ: Involvement of reactive oxygen species, but not mitochondrial permeability transition in the apoptotic induction of human SK-Hep-1 hepatoma cells by shikonin. Planta Med 69 $1119-1124,2003$.
24. Min R, Tong J, Wenjun Y, Wenhu D, Xiaojian Z, Jiacai H, Jian Z, Wantao $C$ and Chenping Z: Growth inhibition and induction of apoptosis in human oral squamous cell carcinoma Tca-8113 cell lines by Shikonin was partly through the inactivation of NF-kappaB pathway. Phytother Res 22: 407-415, 2008.

25. Yao Y and Zhou Q: A novel antiestrogen agent Shikonin inhibits estrogen-dependent gene transcription in human breast cancer cells. Breast Cancer Res Treat 121: 233-240, 2010.

26. Yingkun N, Lvsong Z and Huimin Y: Shikonin inhibits the proliferation and induces the apoptosis of human HepG2 cells. Can J Physiol Pharmacol 88: 1138-1146, 2010.

27. Chang IC, Huang YJ, Chiang TI, Yeh CW and Hsu LS: Shikonin induces apoptosis through reactive oxygen species/extracellular signal-regulated kinase pathway in osteosarcoma cells. Biol Pharm Bull 33: 816-824, 2010.

28. Yang H, Zhou P, Huang $\mathrm{H}$, et al: Shikonin exerts antitumor activity via proteasome inhibition and cell death induction in vitro and in vivo. Int I Cancer 124: 2450-2459, 2009.

29. Wu Z, Wu LJ, Li LH, Tashiro S, Onodera S and Ikejima T: Shikonin regulates HeLa cell death via caspase-3 activation and blockage of DNA synthesis. J Asian Nat Prod Res 6: $155-166,2004$

30. Afford S and Randhawa S: Apoptosis. Mol Pathol 53: 55-63, 2000 .

31. Lee DH, Kim C, Zhang L and Lee YJ: Role of p53, PUMA, and Bax in wogonin-induced apoptosis in human cancer cells. Biochem Pharmacol 75: 2020-2033, 2008.

32. Donovan $M$ and Cotter TG: Control of mitochondrial integrity by Bcl-2 family members and caspase-independent cell death. Biochim Biophys Acta 1644: 133-147, 2004.

33. Anilkumar U and Prehn JH: Anti-apoptotic BCL-2 family proteins in acute neural injury. Front Cell Neurosci 8: 281, 2014.

34. Wang W, Guo Q, You Q, et al: Involvement of bax/bcl-2 in wogonin-induced apoptosis of human hepatoma cell line SMMC-7721. Anticancer Drugs 17: 797-805, 2006.

35. Taylor WR and Stark GR: Regulation of the G2/M transition by p53. Oncogene 20: 1803-1815, 2001.

36. Kastan MB and Kuerbitz SJ: Control of G1 arrest after DNA damage. Environ Health Perspect 101: 55-58, 1993.

37. Lee DH, Rhee JG and Lee YJ: Reactive oxygen species up-regulate p53 and Puma; a possible mechanism for apoptosis during combined treatment with TRAIL and wogonin. Br J Pharmacol 157: 1189-1202, 2009.

38. Li Y, Qu X, Qu J, Zhang Y, Liu J, Teng Y, Hu X, Hou K and Liu Y: Arsenic trioxide induces apoptosis and $\mathrm{G}_{2} / \mathrm{M}$ phase arrest by inducing $\mathrm{Cbl}$ to inhibit PI3K/Akt signaling and thereby regulate p53 activation. Cancer Lett 284: 208-215, 2009.

39. Scorrano L, Oakes SA, Opferman JT, Cheng EH, Sorcinelli MD, Pozzan T and Korsmeyer SJ: BAX and Bak regulation of endoplasmic reticulum $\mathrm{Ca} 2+$ : a control point for apoptosis. Science 300: 135-139, 2003.

40. Datta SR, Brunet A and Greenberg ME: Cellular survival: A play in three Akts. Genes Dev 13: 2905-2927, 1999.

41. Brader S and Eccles SA: Phosphoinositide 3-kinase signalling pathways in tumor progression, invasion and angiogenesis. Tumori 90: 2-8, 2004.

42. Suthiphongchai T, Promyart P, Virochrut S, Tohtong R and Wilairat P: Involvement of ERKI/2 in invasiveness and metastatic development of rat prostatic Adenocarcinoma. Oncol Res 13: 253-259, 2003.

43. Tang YQ, Jaganath I, Manikam R and Sekaran SD: Phyllanthus suppresses prostate cancer cell, PC-3, proliferation and induces apoptosis through multiple signalling pathways (MAPKs, PI3K/Akt, NFאB and Hypoxia). Evid Based Complement Alternat Med 2013: 609581, 2013.

44. Gong K and Li W: Shikonin, a Chinese plant-derived naphthoquinone, induces apoptosis in hepatocellular carcinoma cells through reactive oxygen species: A potential new treatment for hepatocellular carcinoma. Free Riadic Biol Med 51: 2259-2271, 2011. 